\title{
Rheological behavior of water and ethylene glycol based nanofluids containing oxide nanoparticles
}

\author{
A.V. Minakov ${ }^{1,2}$, V.Ya. Rudyak ${ }^{1,3}$, M.I. Pryazhnikov ${ }^{1,2}$ \\ ${ }^{1}$ Siberian Federal University, Krasnoyarsk, Russia \\ ${ }^{2}$ Kutateladze Institute of Thermophysics, SB RAS, Novosibirsk, Russia \\ ${ }^{3}$ Novosibirsk State University of Architecture and Civil Engineering, Russia
}

E-mail: Aminakov@sfu-kras.ru

The paper presents the results of experimental study of rheological behavior of nanofluids based from consideration of several tens of nanofluids based on water, ethylene glycol and engine oil, containing particles of different oxides and diamond. The sizes of nanoparticles ranged from 5 to $150 \mathrm{~nm}$, while their volume concentration ranged from 0.25 to $8 \%$. At that, no dispersants were used when preparing tested nanofluids. It is shown that in some cases, when increasing nanoparticle concentration, rheological behavior of nanofluids becomes nonNewtonian and is well described by power-law fluid models or Herschel-Bulkley fluids. The influence of nanoparticle size and material, as well as the nature of the base fluid on the rheological behavior of nanofluids have been studied.

Key words: rheology, nanofluid, nanoparticles, viscosity, shear rate, shear stress, nonNewtonian fluids.

\section{Introduction}

Nanofluids, that is, suspensions with nanoparticles, are actively studied for the last twenty years in the context of already existing or planned numerous applications (see, e.g., [1] and references therein). Since nanofluids are used in all practical cases in flow conditions, flow nature is determined by their corresponding thermophysical properties. A huge number of publications are devoted to the study of these properties and primarily the thermal conductivity and viscosity. Currently, through experiments as well as by molecular dynamics method it is securely substantiated that these properties cannot be described by the classical theories. Both viscosity and thermal conductivity of nanofluids depend not only on concentration of particles (as in the case of conventional coarse dispersed fluids), but also on their size and material. Moreover, the viscosity of nanofluids decreases with increasing particle size, while the thermal conductivity, in contrast, increases. 
An important property of nanofluids is that their rheological behavior can differ from behavior of the base fluid. Usually, studied nanofluids are based on water, ethylene glycol, engine oils, etc. All of them are conventional Newtonian fluids. However, nanofluids based on these liquids in a number of cases have non-Newtonian rheological behavior even at relatively low particle concentration. In principle, the study of the rheological behavior of nanofluids is a mandatory attribute, which accompanies measuring its viscosity, since we can speak about the actual viscosity only with regard to a Newtonian fluid. Among quite full reviews [2-5], devoted to the study of the viscosity in nanofluids, there are relatively few works, where their nonNewtonian rheological properties were revealed. This is due to the fact that specialized rheometers were rarely used for this purpose, while in many works, when studying viscosity using rotational viscometers, shear rate did not vary within a sufficiently wide range that is absolutely necessary. Nevertheless, to date, there have been many works, where non-Newtonian nature of the rheological behavior of nanofluid is securely revealed (see the review [6]), although they were prepared based on Newtonian fluids.

For example, in [7], when studying water-based nanofluid with the $\mathrm{TiO}_{2}$ nanoparticles, it was revealed that at low particle volume concentrations, nanofluid was Newtonian. However, at the concentrations above $0.1 \%$ nanofluid was becoming thyrotrophic. Similar data were also obtained later [8].

Non-Newtonian behavior of ethylene glycol-based nanofluids was observed in [9] at the elevated concentration of $\mathrm{Fe}_{2} \mathrm{O}_{3}$ particles, and in [10] for $\mathrm{CuO}$ particles. Water-based nanofluid also turned out to be non-Newtonian with increasing concentration of $\mathrm{Fe}_{3} \mathrm{O}_{4}$ nanoparticles [11].

The change in the rheological behavior of nanofluids with increasing nanoparticle concentration in general should not cause surprise. Similar behavior was observed previously in the study of rheological behavior of classical coarse dispersed fluids. Non-Newtonian behavior of coarse dispersed fluids with increasing concentration of the dispersed particles is a known rule [12-16]. This behavior is due to several reasons, and in particular, it is due to the dispersed fluid structuring [17]. However, as already mentioned, the viscosity of nanofluids depends significantly on the particle size. Nevertheless, in most studies, which were dealt with the change in the rheological behavior of nanofluid with increasing concentration, the size of the particles almost was not varied. Moreover, in some works it is just hard to understand what was taken as an average size of particles used in nanofluid. For example, in the mentioned work [9] it is indicated that particles had the size of $(29 \pm 18) \mathrm{nm}$.

The effect of nanoparticles size on the rheology of nanofluids was discussed in the only paper [18] known to us. In this paper the properties of ethylene glycol based nanofluid with TiN nanoparticles with average diameter 20 and $50 \mathrm{~nm}$ were studied. It was shown that a transition 
from Newtonian fluid to shear-thinning yield stress material with viscoelastic structure is observed which is also sensitive to nanoparticle size. Lower the nanoparticle size, higher is the viscoelastic structure and the yield stress when it is present.

Since in addition to the particle concentration and size the viscosity of nanofluid also depends on the temperature and material of the particle [19-22], it is clear that exactly these characteristics can influence rheological behavior of nanofluids. Finally, it should be noted that often, when preparing stable nanofluids, various dispersants (surfactants) are used for their stabilization. Surfactants usually have a fairly complex structure, and their addition in the base fluid itself can change its structure and consequently the rheological behavior. Thus, it is clear that a possible change in the rheological behavior of nanofluids based on Newtonian fluids can be determined by a large number of parameters that requires systematical study of the influence of each of them. The complexity of experimental investigation of the effect of each of these parameters stems from the fact that it is necessary to study the rheological behavior of a large number of nanofluids, varying just one parameter and leaving the rest unchanged. In this work, on a systematic basis we experimentally studied the rheological behavior of nanofluids based on water, ethylene glycol, and engine oil with particles of various metals dioxide $\left(\mathrm{CuO}, \mathrm{SiO}_{2}, \mathrm{TiO}_{2}\right.$, $\mathrm{Al}_{2} \mathrm{O}_{3}, \mathrm{ZrO}_{2}, \mathrm{Fe}_{2} \mathrm{O}_{3}$, and $\mathrm{Fe}_{3} \mathrm{O}_{4}$ ), as well as diamond. The volume concentrations of particles ranged from 0.1 to $8 \%$, while their size was changed from 5 to $150 \mathrm{~nm}$. We have carried out measurements in more than fifty nanofluids to investigate the effects of particle concentration and their size on the manifestation of non-Newtonian properties in nanofluids.

\section{Used materials and measurement methods}

All nanofluids used in the described experiments were prepared by the so-called two-step method. To prepare nanofluid, nanopowder, containing particles of predetermined average size, was added in certain proportions to the base fluid. Then, the dispersed system was mechanically stirred and subjected to ultrasonic treatment to destroy the conglomerates of nanoparticles. There is no universal prescription concerning the time necessary for ultrasonic treatment of the nanofluid. In our experiments the processing time was determined so that the measured viscosity did not change with increasing treatment time. Usually, when using the "Sapphire SC-10338" ultrasonic bath, this time was 45 minutes. When preparing nanofluids, we have used nanopowders obtained from different manufacturers (see Table 1).

Measurement of viscosity coefficient of the nanofluid was carried out with the help of "Brookfield DV2T" rotational viscometer with interchangeable spindles. The viscosity of waterbased nanofluids was measured using LV-1 spindle and ULA(0) adapter to measure low viscosities. We used also a rotational viscometer OFITE-900. In all cases the accuracy of the 
measurements was not lower $2 \%$. In the course of measuring, shear rates $\dot{\gamma}$ were increased sequentially up to values of $10^{3} \mathrm{~s}^{-1}$.

This allowed studying the dependence of the shear stress tensors of the test fluid on shear rate and thereby determining its rheological properties. The measurements were carried out at a constant temperature. All measurements presented below are performed at $25^{\circ} \mathrm{C}$.

Table 1. Types of used nanopowders for preparing nanofluids

\begin{tabular}{|c|c|c|}
\hline Nano-material & Particle size (nm) & Manufacturer \\
\hline $\mathrm{SiO}_{2}$ & $10,16,25$ and 100 & JSC "Plasmoterm" (Moscow) \\
\hline $\mathrm{Al}_{2} \mathrm{O}_{3}$ & $50,75,100$ and 150 & JSC "Plasmoterm" (Moscow) \\
\hline $\mathrm{TiO}_{2}$ & 71,100 and 150 & JSC “Plasmoterm" (Moscow) \\
\hline $\mathrm{ZrO}_{2}$ & 44 and 105 & JSC "Plasmoterm" (Moscow) \\
\hline $\mathrm{Fe}_{2} \mathrm{O}_{3}$ & 18 and 50 & JSC "Plasmoterm" (Moscow) \\
\hline $\mathrm{Fe}_{3} \mathrm{O}_{4}$ & 50 and 100 & LLC “Advanced powder technology" (Tomsk) \\
\hline $\mathrm{CuO}$ & 100 & LLC “Advanced powder technology" (Tomsk) \\
\hline $\mathrm{C}$ & 5 & FRPC “Altai" \\
\hline
\end{tabular}

\section{Results. The effect of particle concentration on rheological behavior of nanofluids}

The data of the conducted measurements are summarized in Table 2-4. Here the first column indicates the base fluid (BF), the second column corresponds to nanoparticle material $(\mathrm{Np})$, the third column indicates characteristic particle size (D), the fourth shows volume concentration of particles in percent $(\varphi)$, the fifth corresponds to rheological behavior of nanofluid $(\mathrm{Rh})$, namely Newtonian $(\mathrm{N})$ or non-Newtonian $(\mathrm{n}-\mathrm{N})$. Base fluids were water $(\mathrm{W})$, ethylene glycol (EG) and engine oil (O). Table presents about three tens of nanofluids, which differed also in terms of the nanoparticle concentration ranged within enough wide limits. NonNewtonian rheological behavior was revealed in about a fifth of all of the measurements.

Table 2. Rheological properties of the studied water-based nanofluids

\begin{tabular}{|c|c|c|c|c|}
\hline $\mathrm{BF}$ & $\mathrm{Np}$ & $\mathrm{D}, \mathrm{nm}$ & $\varphi, \%$ & $\mathrm{Rh}$ \\
\hline $\mathrm{W}$ & $\mathrm{SiO}_{2}$ & 10 & $0.25-2$ & $\mathrm{~N}$ \\
\hline $\mathrm{W}$ & $\mathrm{SiO}_{2}$ & 16 & $0.25-2$ & $\mathrm{~N}$ \\
\hline $\mathrm{W}$ & $\mathrm{SiO}_{2}$ & 25 & $0.25-2$ & $\mathrm{~N}$ \\
\hline $\mathrm{W}$ & $\mathrm{SiO}_{2}$ & 100 & $0.25-2$ & $\mathrm{~N}$ \\
\hline $\mathrm{W}$ & $\mathrm{Al}_{2} \mathrm{O}_{3}$ & 50 & $1-2$ & $\mathrm{~N}$ \\
\hline $\mathrm{W}$ & $\mathrm{Al}_{2} \mathrm{O}_{3}$ & 75 & $1-2$ & N \\
\hline $\mathrm{W}$ & $\mathrm{Al}_{2} \mathrm{O}_{3}$ & 100 & $1-2$ & N \\
\hline $\mathrm{W}$ & $\mathrm{Al}_{2} \mathrm{O}_{3}$ & 150 & $1-6$ & $\mathrm{~N}$ \\
\hline $\mathrm{W}$ & $\mathrm{TiO}_{2}$ & 71 & 2 & $\mathrm{~N}$ \\
\hline $\mathrm{W}$ & $\mathrm{TiO}_{2}$ & 100 & 2 & N \\
\hline $\mathrm{W}$ & $\mathrm{TiO}_{2}$ & 150 & $1-6$ & $\mathrm{~N}$ \\
\hline $\mathrm{W}$ & $\mathrm{ZrO}_{2}$ & 44 & $2-8$ & $\mathrm{~N}$ \\
\hline $\mathrm{W}$ & $\mathrm{ZrO}_{2}$ & 105 & $2-8$ & $\mathrm{~N}$ \\
\hline $\mathrm{W}$ & $\mathrm{C}$ & 5 & $0.25-2$ & $\mathrm{n}-\mathrm{N}$ \\
\hline
\end{tabular}


Table 3. Rheological properties of the studied ethylene glycol-based nanofluids

\begin{tabular}{|c|c|c|c|c|c|c|}
\hline \multicolumn{5}{|c|}{ Present data } & \multicolumn{2}{|c|}{ Literature data } \\
\hline $\mathrm{BF}$ & $\mathrm{Np}$ & $\mathrm{D}, \mathrm{nm}$ & $\varphi, \%$ & $\mathrm{Rh}$ & Parameters & $\mathrm{Rh}$ \\
\hline EG & $\mathrm{SiO}_{2}$ & 25 & 1 & $\mathrm{~N}$ & $\begin{array}{c}\varphi=0.45-2.3 \% \\
\mathrm{D}=7-14 \mathrm{~nm}\end{array}$ & $\mathrm{~N}$ [23] \\
\hline EG & $\mathrm{SiO}_{2}$ & 100 & 1 & $\mathrm{~N}$ & $\begin{array}{c}\varphi=0.5-7 \% \\
\mathrm{D}=18.1,28.3,45.6 \mathrm{~nm}\end{array}$ & $\mathrm{~N}$ [19] \\
\hline EG & $\mathrm{Al}_{2} \mathrm{O}_{3}$ & 11 & $1-2$ & $n-N$ & \multirow{8}{*}{$\begin{array}{c}\varphi=0.5-6.5 \% \\
D=43 \pm 23 \mathrm{~nm} \\
\varphi=0.5-3 \% \\
D=8 \pm 3 \mathrm{~nm}\end{array}$} & \multirow[t]{8}{*}{ N [24] } \\
\hline EG & $\mathrm{Al}_{2} \mathrm{O}_{3}$ & 50 & $1-2$ & $\mathrm{n}-\mathrm{N}$ & & \\
\hline EG & $\mathrm{Al}_{2} \mathrm{O}_{3}$ & 75 & 1 & $\mathrm{~N}$ & & \\
\hline EG & $\mathrm{Al}_{2} \mathrm{O}_{3}$ & 75 & 2 & $\mathrm{n}-\mathrm{N}$ & & \\
\hline EG & $\mathrm{Al}_{2} \mathrm{O}_{3}$ & 100 & 1 & $\mathrm{~N}$ & & \\
\hline EG & $\mathrm{Al}_{2} \mathrm{O}_{3}$ & 100 & 2 & $n-N$ & & \\
\hline EG & $\mathrm{Al}_{2} \mathrm{O}_{3}$ & 150 & 0.25 & $\mathrm{~N}$ & & \\
\hline EG & $\mathrm{Al}_{2} \mathrm{O}_{3}$ & 150 & $2-6$ & $\mathrm{n}-\mathrm{N}$ & & \\
\hline EG & $\mathrm{CuO}$ & 100 & $0.1-1$ & $\mathrm{~N}$ & & \\
\hline EG & $\mathrm{TiO}_{2}$ & 150 & 0.25 & $\mathrm{~N}$ & $\begin{array}{c}\varphi=1.1-5.8 \% \\
\mathrm{D}=35 \pm 17,47 \pm 18 \mathrm{~nm}\end{array}$ & $\mathrm{n}-\mathrm{N}[25]$ \\
\hline EG & $\mathrm{TiO}_{2}$ & 150 & $2-6$ & $\mathrm{n}-\mathrm{N}$ & $\begin{array}{c}\varphi=0-8 \%, \\
D=40-200 \mathrm{~nm}\end{array}$ & $\mathrm{n}-\mathrm{N}$ if $\varphi>1.2 \%$ [26] \\
\hline EG & $\mathrm{C}$ & 5 & $0.25-2$ & $\mathrm{~N}$ & $\begin{array}{c}\varphi=0.01-0.1 \%, \\
D=4 \mathrm{~nm}\end{array}$ & $\mathrm{n}-\mathrm{N}$ [27] \\
\hline
\end{tabular}

Table 4. Rheological properties of the studied engine oil-based nanofluids

\begin{tabular}{|c|c|c|c|c|c|c|}
\hline \multicolumn{5}{|c|}{ Present data } & \multicolumn{2}{|c|}{ Literature data } \\
\hline $\mathrm{BF}$ & $\mathrm{Np}$ & $\mathrm{D}, \mathrm{nm}$ & $\varphi, \%$ & $\mathrm{Rh}$ & Parameters & $\mathrm{Rh}$ \\
\hline $\mathrm{O}$ & $\mathrm{Fe}_{3} \mathrm{O}_{4}$ & 50 & 1 & $\mathrm{~N}$ & & \\
\hline $\mathrm{O}$ & $\mathrm{Fe}_{3} \mathrm{O}_{4}$ & 100 & 1 & $\mathrm{~N}$ & & \\
\hline $\mathrm{O}$ & $\mathrm{Fe}_{2} \mathrm{O}_{3}$ & 18 & 1 & $\mathrm{~N}$ & $\varphi=0-6.6 \%$ & $\mathrm{n}-\mathrm{N}$ [9] \\
\hline $\mathrm{O}$ & $\mathrm{Fe}_{2} \mathrm{O}_{3}$ & 50 & 1 & $\mathrm{~N}$ & $\mathrm{D}=29 \pm 18 \mathrm{~nm}$ & \\
\hline $\mathrm{O}$ & $\mathrm{C}$ & 5 & $0.25-2$ & $n-N$ & & \\
\hline
\end{tabular}

The first experimental series was aimed at clarifying the nature of the change in the rheological behavior of tested nanofluids at varying concentration of particles. Non-Newtonian behavior was demonstrated by ethylene glycol-based nanofluids with particles of aluminum and titanium oxides. In both cases the nanoparticles sizes were very close and equal to $150 \pm 5 \mathrm{~nm}$. We have studied four volume concentrations of nanoparticles, namely $0.25,2,4$, and $6 \%$. The shear rate $\dot{\gamma}$ was varied from 0.4 to $80 \mathrm{~s}^{-1}$. The dependence of the viscosity coefficient $\mu$ on shear rate is shown in Fig. 1a. In both cases there is a pronounced non-Newtonian rheological behavior of nanofluid, which strengthens with increasing concentration of nanoparticles. At that, pure ethylene glycol is a Newtonian fluid. At low concentrations of nanoparticles, all tested nanofluids were characterized by Newtonian rheological behavior $(\varphi \leq 0.25 \%)$. Thus, we can 
state that the transition from Newtonian to non-Newtonian rheological behavior of nanofluids takes place when increasing concentration of nanoparticles. The same rheological behavior was observed in our previous works [28-30], when studying rheological properties of water-based nanofluids with particles of $\mathrm{CuO}$ (although, there was used surfactant). At the concentration of particles equal to $0.25 \%$ the nanofluid was Newtonian, while with increasing particle concentration fluid became non-Newtonian.

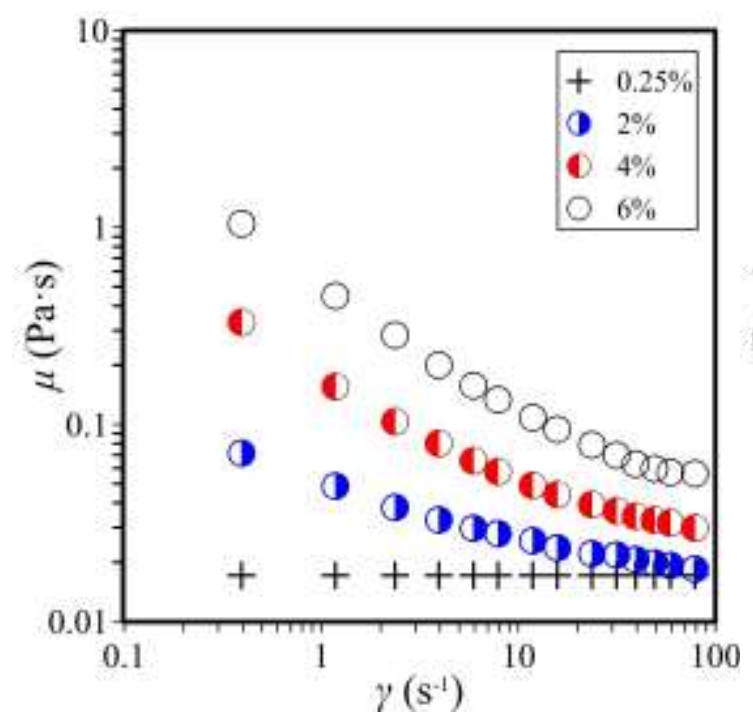

(a)

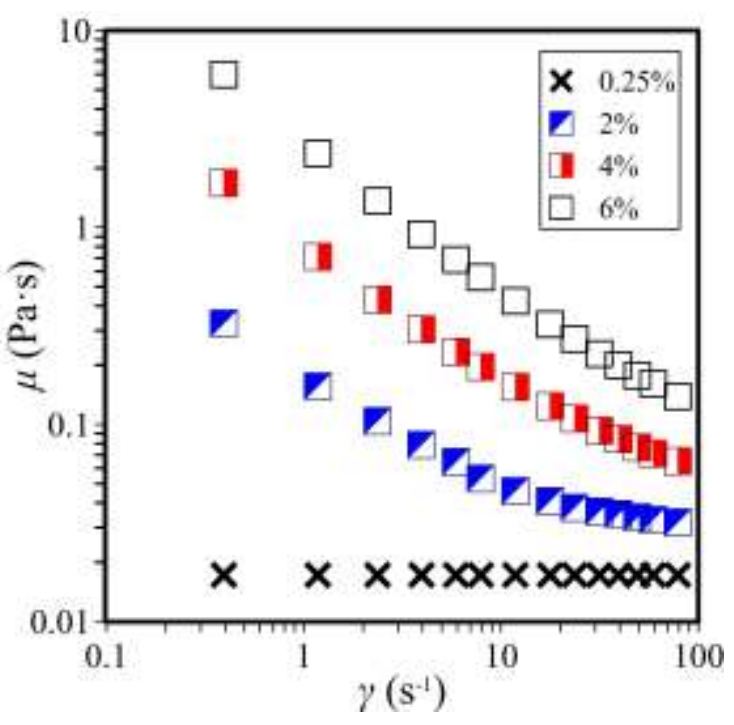

(b)

Fig. 1. Viscosity coefficient versus shear rate for ethylene glycol-based nanofluids with $150 \mathrm{~nm}$ particles of $\mathrm{Al}_{2} \mathrm{O}_{3}$ (a) and $\mathrm{TiO}_{2}$ (b).

To establish the nature of rheological behavior of nanofluids, it is necessary to study the dependence of its stress tensor $\tau$ on shear rate. For tested nanofluids this dependence is shown in Fig. 2. Presented dependences have a qualitatively different nature. At high particle concentrations (4 and 6\%) we observed the presence of a limit stress, whereas at the smallest concentration (2\%) within the measurement accuracy noted stress was not revealed. The dependencies presented in Fig. 1 show that nanofluids demonstrate pseudoplastic or viscoplastic behavior, i.e. their molecular viscosity decreases with increasing shear rate (in viscoplastic fluids this happens starting at some limiting stress value) [31, 32]. In the first case, to describe such fluids, a power-law fluid model is usually used 


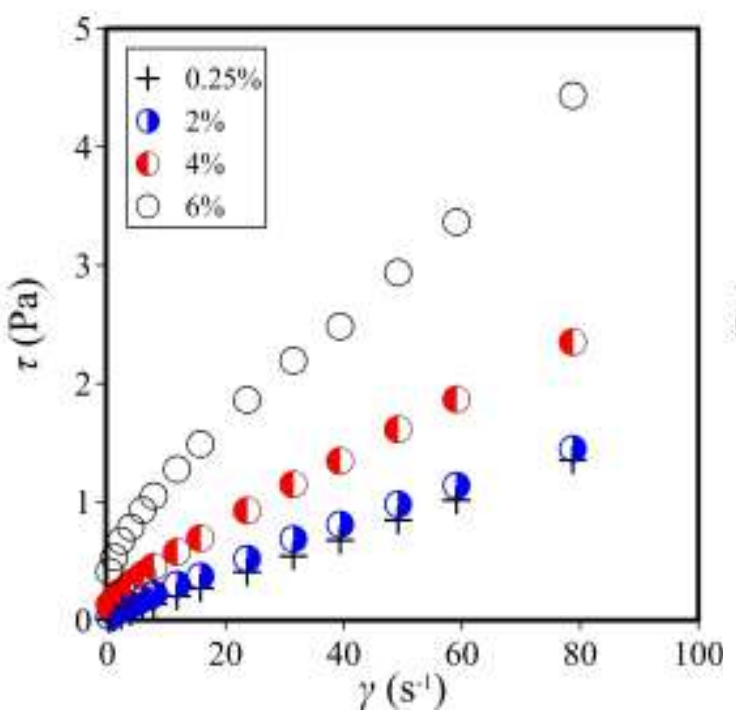

(a)

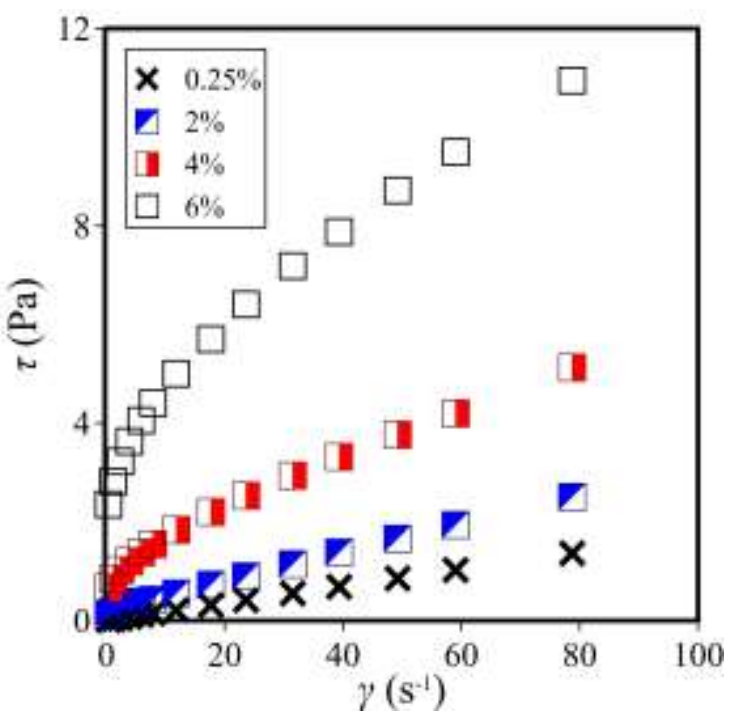

(b)

Fig. 2. Stress tensor versus shear rate for ethylene glycol-based nanofluids with $150 \mathrm{~nm}$ particles of $\mathrm{Al}_{2} \mathrm{O}_{3}$ (a) and $\mathrm{TiO}_{2}$ (b).

$$
\mu=k_{v} \dot{\gamma}^{n-1},
$$

while in the second case Herschel-Bulkley fluid model is applicable

$$
\mu_{f}=\left(\tau_{0}+k_{v} \dot{\gamma}^{n}\right) \dot{\gamma}^{-1} \text {. }
$$

Here, $\tau_{0}-$ is the yield stress of viscoplastic fluid, $n-$ is the fluid index, while $k_{v}-$ is the consistency factor.

Table 5. Consistency factors and fluid index of ethylene glycol-based nanofluids with nanoparticles of $\mathrm{Al}_{2} \mathrm{O}_{3}$ and $\mathrm{TiO}_{2}$ (Power-law fluid model)

\begin{tabular}{|c|c|c|c|}
\hline \multicolumn{2}{|c|}{$\mathrm{Al}_{2} \mathrm{O}_{3}$} & \multicolumn{2}{c|}{$\mathrm{TiO}_{2}$} \\
\hline$k_{v}, \mathrm{mPa} \cdot \mathrm{s}^{n}$ & $n$ & $k_{v}, \mathrm{mPa} \cdot \mathrm{s}^{n}$ & $n$ \\
\hline 52.0 & 0.745 & 256 & 0.542 \\
\hline
\end{tabular}

The obtained experimental data were used to construct relevant correlations. As a result, it was shown that with a high accuracy (validity coefficient is equal to 0.999) the tested nanofluids at the concentration of particles equal to $2 \%$ are described by model (1), while at higher concentrations - by model (2). In the latter case, the validity coefficient for the nanofluid with particles of $\mathrm{Al}_{2} \mathrm{O}_{3}$ is equal to 1 and 0.997 , while for the nanofluid with particles of $\mathrm{TiO}_{2}$ it was 0.999 and 1 for the concentrations of 4 and $6 \%$, respectively. Correlation parameters of the power-law fluid at the particle concentration of $2 \%$, as well as Herschel-Bulkley fluid for higher concentrations are shown in Tables 5 and 6. The fluid index decreases with the increase in the particle concentration, while consistency factor, on the contrary, increases, as well as the limiting stress. 
Table 6. Yield stress and rheological parameters of ethylene glycol-based nanofluids with nanoparticles of $\mathrm{Al}_{2} \mathrm{O}_{3}$ and $\mathrm{TiO}_{2}$ (Herschel-Bulkley fluid model)

\begin{tabular}{|c|c|c|c|c|c|c|}
\hline \multirow{2}{*}{$\varphi, \%$} & \multicolumn{2}{|c|}{$\mathrm{Al}_{2} \mathrm{O}_{3}$} & & \multicolumn{2}{c|}{$\mathrm{TiO}_{2}$} & \\
\cline { 2 - 7 } & $\tau_{0}, \mathrm{mPa}$ & $k_{v}, \mathrm{mPa} \cdot \mathrm{s}^{n}$ & $n$ & $\tau_{0}, \mathrm{mPa}$ & $k_{v}, \mathrm{mPa} \cdot \mathrm{s}^{n}$ & $n$ \\
\hline 4 & 121.8 & 57.67 & 0.835 & 615.5 & 212.4 & 0.696 \\
\hline 6 & 382.3 & 140.0 & 0.746 & 2044 & 695.0 & 0.582 \\
\hline
\end{tabular}

In studies [20,21] it was shown by the molecular dynamics method that the viscosity of nanofluids depends on the material of the particles (at identical particle concentrations and size). Later on this was confirmed experimentally [22]. It turned out that the rheological behavior of nanofluid also essentially depends on material of the particles. In the described experiments we used, in particular, particles of titanium and aluminum oxides having an average particle size of $150 \mathrm{~nm}$. However, their rheological characteristics at the same particle concentration were significantly different. These differences are illustrated in Fig. 3, showing viscosity and stress depending on the shear rate at the particle concentration of $6 \%$. The viscosity as well as shear stress of nanofluid with $\mathrm{TiO}_{2}$ particles is higher than those in nanofluids with $\mathrm{Al}_{2} \mathrm{O}_{3}$ particles.

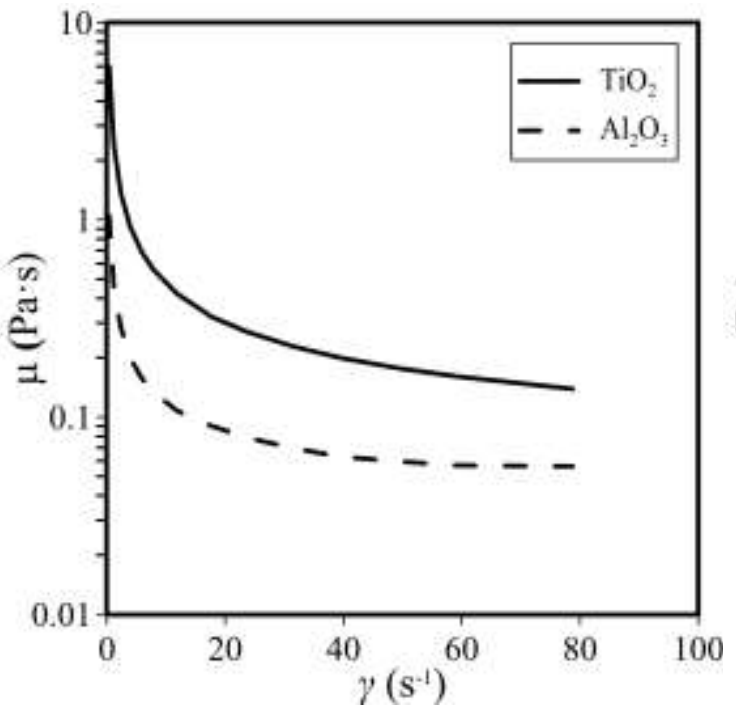

(a)

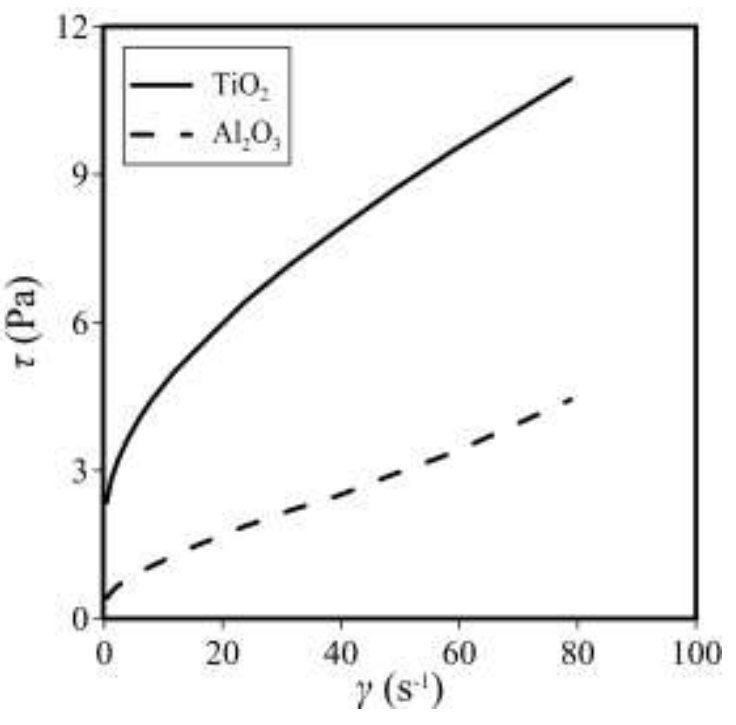

(b)

Fig. 3. Viscosity (a) and shear stress (b) versus shear rate for ethylene glycol-based nanofluid with $\mathrm{Al}_{2} \mathrm{O}_{3}$ and $\mathrm{TiO}_{2}$ a particles $(\mathrm{D}=150 \mathrm{~nm})$ at $\varphi=6 \%$.

\section{Results. The effect of nanoparticle size on rheological behavior of nanofluids}

It was indicated above that the viscosity and conductivity of nanofluids depend not only on the concentration of nanoparticles, but also their size. If we recall that nanoparticles are particles with characteristic sizes ranged from 1 to $100 \mathrm{~nm}$, this becomes quite clear. Even at low concentrations of nanoparticles, say $1 \%$, the numerical density of nanoparticles in the disperse fluid is very large. Particles, starting from a certain critical size, actively interact with each other. 
In addition to this, the fluid near the nanoparticles is structured [33]. Therefore, if nanoparticles are sufficiently small, the whole dispersion fluid is structured. For this reason, we should expect that a possible change of rheological behavior of nanofluids should depend also on the size of nanoparticles. To test this, we have performed a series of measurements for ethylene glycolbased nanofluids with a volume concentration of $1 \%$, but with different particles size of $\mathrm{Al}_{2} \mathrm{O}_{3}$ equal to 11, 50, 75 and $100 \mathrm{~nm}$ (see Table 3). The obtained dependence of the molecular viscosity coefficient on shear rate is presented in Fig. 4a. Nanofluids with large particles (75 and $100 \mathrm{~nm}$ ) are Newtonian fluids, whereas with decreasing of particle size, they exhibit nonNewtonian behavior. The nature of rheological behavior is determined by the dependence of stresses on shear rate. Relevant data are shown in Fig. 4b. In principle, the rheological behavior of the considered nanofluids at small particle sizes is well described by the power-law fluid model (1), where $k_{v}=96.8 \mathrm{mPa} \cdot \mathrm{s}^{\mathrm{n}} ; n=0.572$ for nanofluids with particles of $11 \mathrm{~nm}$, and $k_{v}=28.1$ $\mathrm{mPa} \cdot \mathrm{s}^{\mathrm{n}} ; \mathrm{n}=0.850$ - for nanofluids with particles of $50 \mathrm{~nm}$. It should also be noted that in the nanofluid with the smallest particles, it seems that the appearance of ultimate stresses is possible (see Fig. 4b). However, the measurements accuracy at low shear rates proved to be insufficient to give a definite answer.

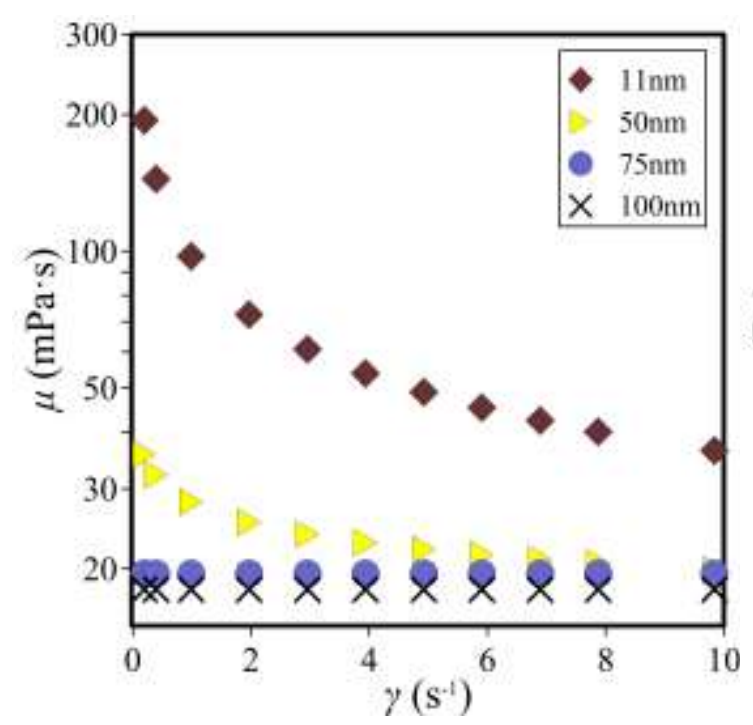

(a)

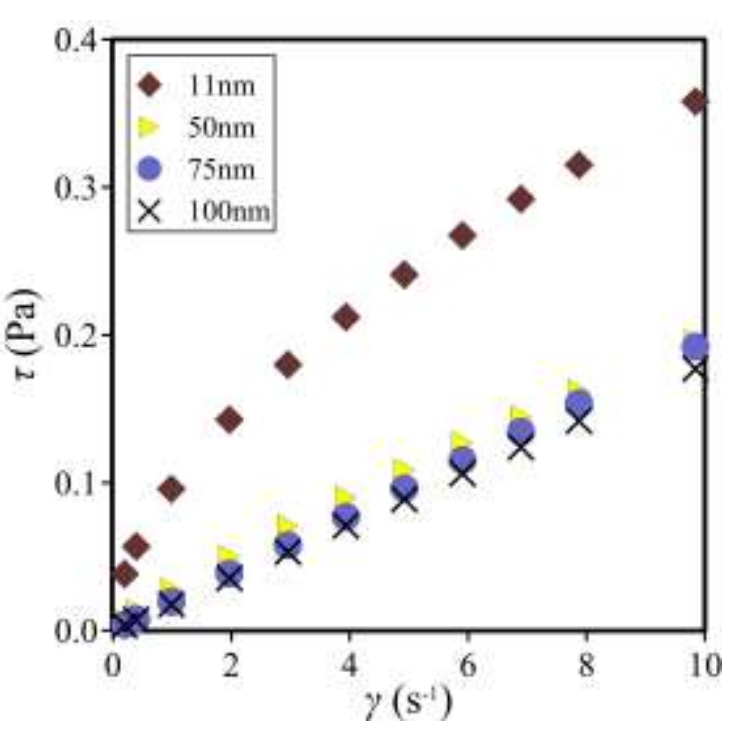

(b)

Fig. 4. Viscosity (a) and shear stress (b) of ethylene glycol-based nanofluid containing particles of $\mathrm{Al}_{2} \mathrm{O}_{3}$ versus shear rate.

\section{Results. The effect of base fluid on the rheological behavior of nanofluid}

Certainly, it is clear from general considerations that the base fluid should also have an effect on the rheological behavior of nanofluid. Though, the reasons for such influence have yet to be understood. In the experiments presented in this paper, the effect of the base fluid was studied using nanofluids with diamond particles. At that, water, ethylene glycol, and engine oil 
were used as the base fluids (Tables 2-4). It turned out that ethylene glycol-based nanofluid is a Newtonian fluid, whereas nanofluids based on water and engine oil, are non-Newtonian fluids. In all cases, the volume concentration of the particles ranged from 0.25 to $2 \%$. The results obtained for water based nanofluid are shown in Fig. 5. The degree of non-Newtonian nature of the fluid increases with increasing particle concentration, though, nanofluid with the lowest investigated concentration of particles was non-Newtonian as well. The rheological behavior of this nanofluid is well described by the model (1). In this case the fluid index decreases with increasing particle concentration, while the consistency factor, on the contrary, increases (Table 7), as for all already described nanofluids. It is quite possible that limiting stresses at low shear rates have small values.

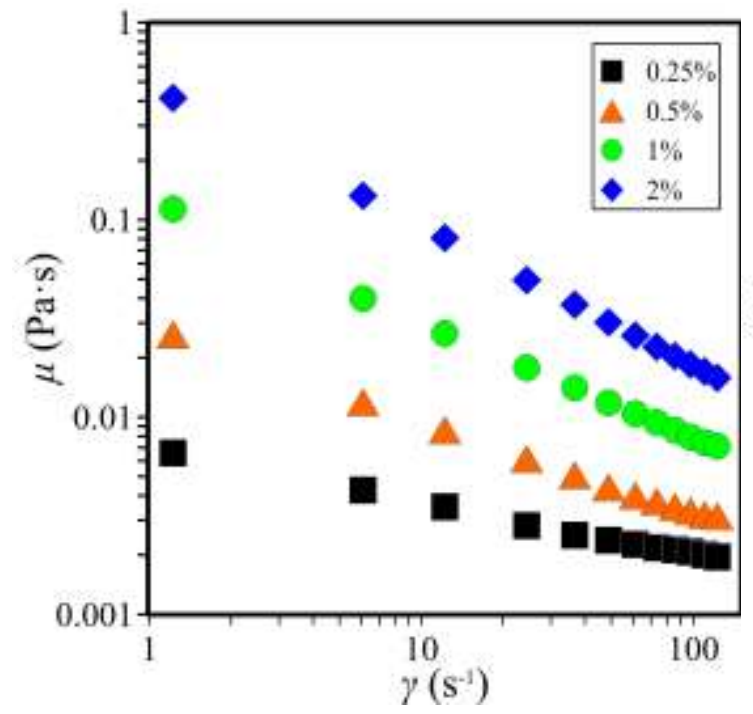

(a)

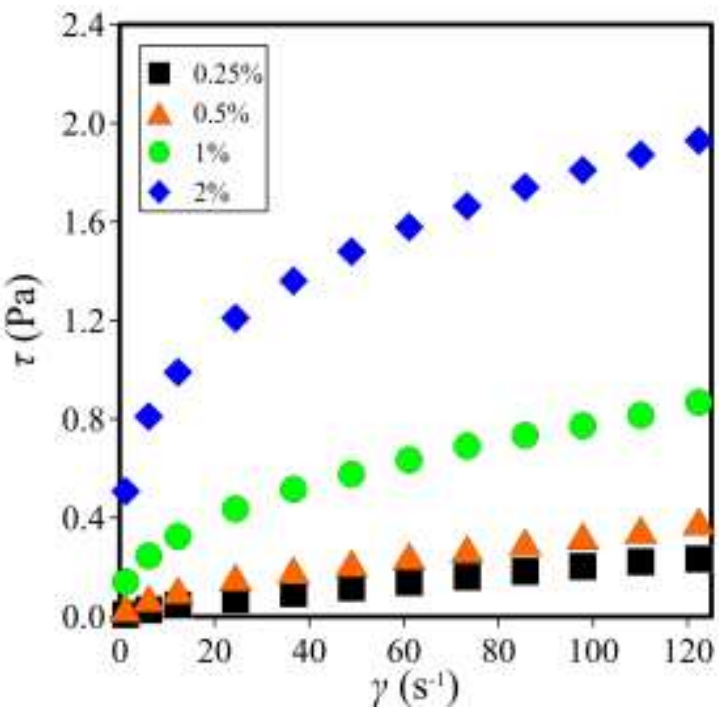

(b)

Fig. 5. Viscosity (a) and shear stress (b) of water-based nanofluid with diamond particles versus shear rate.

Table 7. Parameters of the model (1) for water-based nanofluids with diamond particles

\begin{tabular}{|c|c|c|}
\hline$\varphi, \%$ & $n$ & $k_{v}, \mathrm{mPa} \cdot \mathrm{s}^{n}$ \\
\hline 0.25 & 0.84 & 6.37 \\
\hline 0.50 & 0.55 & 24.0 \\
\hline 1.00 & 0.42 & 101 \\
\hline 2.00 & 0.29 & 479 \\
\hline
\end{tabular}

\section{Conclusion}

The paper presents the rheological properties of several tens of nanofluids based on water, ethylene glycol, and engine oil with nanoparticles of various oxides and diamond. Particle concentrations and their sizes were varied within quite wide range. Tested nanofluids did not contain any dispersants, while the base fluid was Newtonian liquid. It is revealed that in some cases, nanofluids are characterized by non-Newtonian rheological behavior. 
The emergence of non-Newtonian properties is caused by several factors, such as the concentration of nanoparticles, their size and material, as well as properties of the base fluid. The change in rheological behavior from Newtonian to non-Newtonian pattern occurs with increasing nanoparticle concentration. All investigated non-Newtonian nanofluids turned out to be either pseudoplastic or viscoplastic. In the first case the rheological behavior of nanofluids is well described by the power-law fluid model (1). At that, the increase of the particle concentration leads to decrease of fluid index, while consistency factor increases. Viscoplastic fluids are characterized by existence of limiting shear stress, and their rheological behavior is described by Herschel-Bulkley fluid model (2). Here again, as the concentration of particles increases, the fluid index decreases, while the consistency factor increases. It is important to emphasize that increasing the concentration of particles in non-Newtonian nanofluid may change its rheological model. Thus, the pseudoplastic fluid acquires a limiting shear stress and becomes viscoplastic.

Particle size is another important parameter determining the rheological behavior of nanofluids. It is revealed that the transition from Newtonian behavior to non-Newtonian one in some cases occurs at a given volume concentration with decreasing size of nanoparticles. Apparently, we can argue that nanofluids with fairly small particles will always obey nonNewtonian rheological behavior, if only their concentrations are not too small. Finally, the rheology of nanofluids with particles of the same size produced from different materials, in general case, will also be different.

The base fluid properties are also an important factor determining the rheological behavior of nanofluids. In this regard, we must again note that in practice many nanofluids are produced using various dispersants. In this case, the base fluid should be considered as a mixture of initial liquid plus the dispersant. Adding dispersants on its own can change the rheological behavior of the base fluid. However, even in those cases, where base fluid with added dispersant is Newtonian the addition of nanoparticles can alter its rheological properties. Systematic study of the effect of dispersants on the rheological properties of nanofluids will be carried out in the framework of a special study.

It should be noted that ethylene glycol (EG) based nanofluids may have viscoelastic structure. These properties were fixed in several papers [9, 18, 27, 34-36]. The EG nanofluids with $\mathrm{Fe}_{2} \mathrm{O}_{3}$ particles $(29 \pm 18 \mathrm{~nm})$ showing shear thinning and thixotropy [9]. A continuous evolution with concentration from viscous to elastic nature is observed.

In recent paper [27] the viscoelastic behavior fixed in two EG nanofluids with nanodiamonds particles at very small concentrations (mass fraction from 0.01 to 0.1 ). It was presented that both examined nanofluid exhibit viscoelastic structure, with high value of storage 
modulus. The critical deformation in which the structure begins to be destroyed decreases with increasing of volume fraction of the nanoparticles.

As we mentioned in introduction the viscoelastic behavior of the EG based nanofluids with TiN nanoparticles (20 and $50 \mathrm{~nm}$ ) was described in paper [18]. There is the critical concentration of the nanoparticles when the viscoelastic structure was formed.

The viscoelastic behavior of the EG based nanofluids is very important properties from point of view of future applications. The rheology change observed indicates structural changes in the nanofluids as compare with based fluid. However this subject still poorly studied that deserves further attention.

\section{Acknowledgment}

The study has been conducted at partial financial support of the Russian Foundation for Basic Research (grants No. 17-01-00040 and No. 17-58-45032) and Russian Science Foundation (project № 17-79-20218).

\section{References}

1. V.Ya. Rudyak, A.V. Minakov, Modern problems of micro- and nanoflows, Nauka, Novosibirsk, 2016.

2. S.Sh. Hosseini, A. Shahrjerdi, Y. Vazifeshenas, A review of relations for physical properties of nanofluids, Aust. J. Basic and Appl. Sci., 5 (2011) 417-435.

3. I.M. Mahbubul, R. Saidur, M.A. Amalina, Latest developments on the viscosity of nanofluids, Int. J. Heat Mass Transfer, 55 (2012) 874-885.

4. S.M.S. Murshed, P. Estellé, A state of the art review on viscosity of nanofluids. Renew. Sust. Energ. Rev., 76 (2017) 1134-1152.

5. D.H. Koca, S. Doganay, A. Turgut, I.H. Tavman, R. Saidurd, I.M. Mahbubulf, Effect of particle size on the viscosity of nanofluids: A review. Renew. Sust. Energ. Rev., 82 (2018) $1664-1674$.

6. A.K. Sharma, A.K. Tiwari, A.R. Dixit, Rheological behavior of nanofluids: A review, Renew. Sust. Energ. Rev., 53 (2016) 779-791.

7. W.J. Tseng, K.C. Lin, Rheology and colloidal structure of aqueous $\mathrm{TiO}_{2}$ nanoparticle suspensions, Mater. Sci. Eng., A, 355 (2003) 186-192.

8. Y. He, Y. Jin, H. Chen, Y. Ding, D. Cang, H. Lu, Heat transfer and flow behavior of aqueous suspensions of $\mathrm{TiO}_{2}$ nanoparticles (nanofluids) flowing upward through a vertical pipe, Int. J. Heat Mass Transfer, 50 (2007) 2272-2276.

9. M. Pastoriza-Gallego, L. Lugo, J. Legido, M. Piñeiro, Rheological non-Newtonian behavior of ethylene glycol-based $\mathrm{Fe}_{2} \mathrm{O}_{3}$ nanofluids, Nanoscale Res. Lett., 6:560 (2011) 1-7. 
10. K. Kwak, C. Kim, Viscosity and thermal conductivity of copper oxide nanofluid dispersed in ethylene glycol, Korea-Aust. Rheol. J., 17(2) (2005) 35-40.

11. R.Y. Hong, Z.Q. Ren, Y.P. Han, H.Z. Li, Y. Zheng, J. Ding, Rheological properties of water-based $\mathrm{Fe}_{3} \mathrm{O}_{4}$ ferrofluids, Chem. Eng. Sci., 62(21) (2007) 5912-5924.

12. R. Tanner, Engineering Rheology. Clarendon Press Oxford, New York, 1985.

13. I. Morrison, S. Ross, Colloidal Dispersions: Suspensions, Emulsions, Foams. 6th ed. WileyInterscience, New York, 2002.

14. R. Pal, Fundamental rheology of disperse systems based on single-particle mechanics, Fluids, 1(40) (2016) 1-49.

15. T.F. Tadros, Rheology of Dispersions. Principles and Applications. WILEY-VCH, Verlag GmbH \& Co., KGaA, Weinheim, 2010.

16. E.E. Bibik, Rheology of disperse systems, LGU, Leningrad, 1981.

17. V.N. Matvienko, E.A. Kirsanov, Viscosity and structure of disperse systems, Moscow University Chemistry Bulletin, 66:199 (2011) 243-276.

18. G. Źyła, J. Fal, P. Estellé, Thermophysical and dielectrical profiles of ethylene glycol based titanium nitride (TiN-EG) nanofluids with various size of particles, Int. J. Heat Mass Transfer, 113 (2017) 1189-1199.

19. V.Ya. Rudyak, S.V. Dimov, V.V. Kuznetsov, On dependence of nanofluid viscosity coefficient on particle size and temperature, Tech. Phys. Lett., 39(17) (2013) 53-59.

20. V.Ya. Rudyak, S.L. Krasnolutskii, Dependence of the viscosity of nanofluids on nanoparticle size and material, Phys. Lett., 378 (2014) 1845-1849.

21. V.Ya. Rudyak, S.L. Krasnolutsky, Modeling of the nanofluid viscosity coefficient by molecular dynamics method, Tech. Phys., 85(6) (2015) 9-16.

22. V.Ya. Rudyak, A.V. Minakov, M.S. Smetanina, M.I. Pryazhnikov, Experimental data on the dependence of the viscosity of water-based and ethylene glycol-based nanofluids on particle size and material, Doklady Phys., 467(3) (2016) 289-291.

23. G. Źyła, J. Fal, Viscosity, thermal and electrical conductivity of silicon dioxide-ethylene glycol transparent nanofluids: An experimental studies, Thermichim. Acta, 650 (2017) 106113.

24. M.J. Pastoriza-Gallego, L. Lugo, J.L. Legido, M.M. Piñeiro, Thermal conductivity and viscosity measurements of ethylene glycol-based $\mathrm{Al}_{2} \mathrm{O}_{3}$ nanofluids, Nanoscale Res. Lett., 6 (221) (2011) 1-11.

25. D. Cabaleiro, M.J. Pastoriza-Gallego, C. Gracia-Fernández, M.M. Piñeiro, L.Lugo, Rheological and volumetric properties of $\mathrm{TiO}_{2}$-ethylene glycol nanofluids, Nanoscale Res. Lett., 8 (2013) 1-13. 
26. R. Shu, Y. Gun, H. Lv, D. Tan, Preparation and rheological behavior of ethylene glicolbased $\mathrm{TiO}_{2}$ nanofluids, Colloids Surf., A, 509 (2016) 86-90.

27. G. Źyła, J.P. Vallejo, J. Fal., L. Lugu, Nanodiamonds - ethylene glycol nanofluids: Experimental investigation of fundamental physical properties, Int. J. Heat Mass Transfer, 121 (2018) 1201-1213.

28. D.V. Guzei, A.V. Minakov, V.Ya. Rudyak, A.A. Dekterev, Measuring the heat-transfer coefficient of nanofluid based on copper oxide in a cylindrical channel, Tech. Phys. Lett., 40(3) (2014) 203-206.

29. A.V. Minakov, V.Ya. Rudyak, D.V. Guzei, A.S. Lobasov, Measurement of the heat transfer coefficient of a nanofluid based on water and copper oxide particles in a cylindrical channel, High Temp., 53(2) (2015) 246-253.

30. A.V. Minakov, A.S. Lobasov, D.V. Guzei, M.I. Pryazhnikov, V.Ya. Rudyak, The experimental and theoretical study of laminar forced convection of nanofluids in the round channel, Appl. Therm. Eng., 88 (2015) 140-148.

31. R.W. Johnson, Handbook of Fluid Dynamics, CRC Press LLC, Boca Raton, 1998.

32. R.P. Chhabra, J.F. Richardson, Non-Newtonian flow and applied rheology, ButterworthHeinemann, Oxford, 2008.

33. V.Ya. Rudyak, Viscosity of nanofluids. Why it is not described by the classical theories. Advances in Nanoparticles, 2(3) (2013) 266-279.

34. G. Źyła, J. Fal., P. Estellé, The influrnce of ash content of thermophysical properties of ethylene glycol based graphite/diamonds mixture nanofluids, Diamond Relat. Mater., 74 (2017) 81-89.

35. A. Mariano, M.J. Pastoriza-Gallego, L.Lugo, A Camacho, S. Canzonieri, M.M. Piñeiro, Thermal conductivity, rheological behaviour and density of non-Newtonian ethylene glycolbased $\mathrm{SnO}_{2}$ nanofluids, Fluid Phase Equilibr., 447 (2013) 119-124.

36. G. Źyła, A. Witek, M. Gizowska, Rheological profile of boron nitride-ethylene glycolnanofluids, J. Appl. Phys., 117 (2015) 014302. 